\title{
VIVER E ESCREVER: HISTÓRIA E EDUCAÇÃO NO ACERVO DE CADERNOS DE UM PROFESSOR CATARINENSE (SÉCULO XX) ${ }^{1}$
}

\author{
Maria Teresa Santos Cunha \\ Universidade do Estado de Santa Catarina/UDESC \\ mariatsc@gmail.com \\ Flavia de Freitas Souza \\ Universidade do Estado de Santa Catarina/UDESC \\ flavia.freitassouza@gmail.com
}

\begin{abstract}
RESUMO
Este estudo tem como material empírico o conjunto de 45 cadernos pessoais deixados pelo professor e intelectual catarinense, Victor Márcio Konder (1920 - 2005), antigo docente da Universidade do Estado de Santa Catarina (UDESC, 1980) que também atuou nas fileiras do Partido Comunista Brasileiro (PCB) nos anos de 1935 a 1956, sendo estes doação póstuma de sua família ocorrida, no ano de 2009, ao acervo do Laboratório de Patrimônio Cultural (LABPAC UDESC). Analisados como registros de uma trajetória, esses manuscritos contêm indícios sobre a formação, interesses de leitura, hábitos de escrita e formas de relacionar-se com o conhecimento que configuraram esse intelectual, professor nas décadas de 60 a 80 do século XX. Além de possibilitar o mapeamento de alguns aspectos da vida do proprietário o estudo também destaca os vários sentidos dos cadernos: como escritas ordinárias; testemunhas de uma construção de si; relíquias conectadas com uma sensibilidade nostálgica e como uma coleção a ser arquivada como objeto e patrimônio da cultura material da escola.
\end{abstract}

Palavras-chave: Cadernos escolares. Intelectuais. Cultura Escrita. História da Educação.

\section{LIVING AND WRITING: HISTORY AND EDUCATION IN A TEACHER'S PERSONAL COLLECTION OF NOTEBOOKS FROM SANTA CATARINA (XX CENTURY)}

\begin{abstract}
This study is to source the set of 45 personal notebooks left by the professor and intellectual Santa Catarina, Victor Márcio Konder (1920-2005), former teacher of University of the State of Santa Catarina (UDESC, 1980) which was also member of the Brazilian Communist Party (PCB) in the years 1935-1956. The notebooks are a posthumous donation of his family that occurred in 2009, to the Cultural Heritage Laboratory of the acquis (LABPAC - UDESC). Analyzed records as a path, these manuscripts contain clues about the formation, reading interests, writing habits and ways of relating with the knowledge that shaped this intellectual, a professor in the 60's to 80 's of the twentieth century. In addition to enabling the mapping of some aspects of the owner's life the study also highlights the many ways of notebooks: as ordinary written; his witnesses; relics
\end{abstract}

\footnotetext{
${ }^{1}$ Este trabalho mantém o enfoque dado pelas autoras aos acervos pessoais de professores catarinenses, para os quais destacam seu sentido histórico e cultural e ao mesmo tempo propõem novos olhares e abordagens. Partes desse texto já foram articulados em outros estudos relacionados ao tema e que estão listados nas referências.
} 
connected with a nostalgic sensibility and as a collection to be presented as an object and equity of school material culture.

Keywords: Personal Notebooks. Intellectual. Written Culture. History of Education.

\section{O GUARDADOR: PROFESSOR VICTOR MÁRCIO KONDER}

Ao guardar materiais referentes à sua vida, o guardador imortaliza uma época e produz representações e marcas de si mesmo. Objetos pessoais podem criar possibilidades para a realização de uma imagem que se quis preservar de si mesmo. À constituição da memória material há a intenção de perpetuar-se, de "forjar uma glória" (RIBEIRO, 1998, p. 35). Artières percebe nesse procedimento a produção de subjetividade:

\footnotetext{
Dessas práticas de arquivamento do eu se destaca o que poderíamos chamar uma intenção autobiográfica. Em outras palavras, o caráter normativo e o processo de objetivação e de sujeição que poderiam aparecer a princípio, cedem na verdade o lugar a um movimento de subjetivação. [...] Arquivar a própria vida é se pôr no espelho, é contrapor à imagem social a imagem íntima de si próprio, e nesse sentido o arquivamento do eu é uma prática de construção de si mesmo e de resistência. (ARTIÉRES, 1998, p. 11).
}

Victor Márcio Konder (1920-2005), integrou uma família teuto brasileira trazida ao Brasil, nos meados do século XIX, por Marcos Konder Sênior. Este, nascido na Alemanha em uma família de agricultores e tecelões, destacou-se como professor desde cedo, chamando a atenção de Nicolau Malburg, grande comerciante de Itajaí/SC. Conhecendo-o em uma viagem a terra alemã, trouxe o primeiro Konder a habitar no Brasil para que fosse professor de seus filhos em solo nacional.

Ao traçar a genealogia das principais famílias de Itajaí, Rothbarth (2001) atesta que Marcos Konder Júnior dá continuidade aos negócios legados pelo pai - casa-se após certo tempo com Maria Corina Régis, (Dona Sinhá) ${ }^{2}$ uma letrada senhora que havia estudado na Escola Normal da capital, nascendo de sua união o professor Victor Márcio Konder.

Victor Márcio Konder nasceu em Itajaí em 1920 e faleceu em Florianópolis em 2005, tendo o pai como líder do Partido Republicano Catarinense. Quando, em 1930, Getúlio Vargas sobe ao poder apoiado principalmente pela elite gaúcha, a família se muda para o Rio de Janeiro, temendo represálias políticas. Lá, conforme explicita em livro autobiográfico (KONDER, 2002), o

\footnotetext{
${ }^{2}$ Ver: BARRETO, C. M., 2011, p. 137-161.
} 
jovem estudante inicia a vida partidária, alistando-se no Partido Comunista Brasileiro - por não existir na época a Juventude Comunista, Victor Márcio filiou-se diretamente ao partido.

Segundo o livro organizado pela família (2006) Victor, durante a década de 1960, foi jornalista, no Rio de Janeiro no Diário Carioca3 e formou-se em Ciências Sociais pela Universidade Federal do Rio de Janeiro, em 1972. Voltando Santa Catarina foi Diretor do Jornal de Santa Catarina, em Blumenau e, na década de 1980, foi professor de História, Antropologia, Cultura Brasileira e Economia na Faculdade de Educação da Universidade do Estado de Santa Catarina (FAED/UDESC) além de exercer várias funções técnicas e administrativas como superintendente da Fundação Catarinense de Cultura, membro do Conselho Estadual de Cultura e membro criador do da Escola de Governo e Cidadania de Florianópolis, nas décadas de 1980/90.

O acervo pessoal do Professor Victor Márcio Konder chegou à Biblioteca da UDESC em inúmeras caixas de papelão que, sem qualquer ordem e aos punhados foram despejados em uma pequena sala que os abrigaria doravante, até serem arrumados. Se, como lembra Farge (2009), o acervo nasce da desordem, ele também supõe mãos que manipulam e classificam os documentos, olhos que vigiam o escrito, cheiros que despertam memórias. Esta operação parece justificar uma problemática e exigir a presença do historiador que, com eles, pode construir um passado e formular problemas que guiarão suas ações, em um trabalho. O percurso nas caixas onde ficaram os cadernos nas prateleiras apertadas do arquivo levou a um mundo repleto de informações à espera dos questionamentos. Na busca de critérios de legitimação, evidencia-se o estudo dos cadernos pessoais que concentram informações sobre o aluno, o leitor e o professor, considerados como documentos, na perspectiva proposta por Meneses (1998, p. 95):

O que faz de um objeto documento não é, pois, uma carga latente, definida, de informação que ele encerre [...]. É pois a questão do conhecimento que cria o sistema documental. O historiador não faz o documento falar: é o historiador quem fala e a explicitação de seus critérios e procedimentos é fundamental para definir o alcance de sua fala. Toda operação com documentos, portanto, é de natureza retórica.

Para a realização deste estudo, algumas problematizações foram levantadas para a coleção em geral: Quem era o possuidor e o que era possuído? Como entender a historicidade desses materiais? Como tirar do esquecimento este volume de impressos que compõe uma coleção que se substantiva em milhares de páginas encadernadas, algumas ostentando marcas de leitura, que

\footnotetext{
${ }^{3}$ O Diário Carioca foi um periódico fundado no Rio de Janeiro em 17 de julho de 1928 por José Eduardo de Macedo Soares e publicado até dezembro de 1965. O Diário Carioca não sobreviveu ao regime militar instalado em 1964 no país, por ser um feroz opositor do governo. Ver: COSTA, 2011.
} 
sobreviveram ao desgaste do tempo e ao perigo do esquecimento? Qual o sentido histórico, político e cultural dessa coleção que envolve 600 livros e 45 cadernos de anotações de seu proprietário? Neste trabalho, os cadernos merecerão atenção destacada.

Figura 1: Fotografia do casal Victor Marcio Konder e Dna. Rosa Konder, quem doou o acervo de livros e cadernos do professor ao Laboratório de Patrimônio Cultural - UDESC.

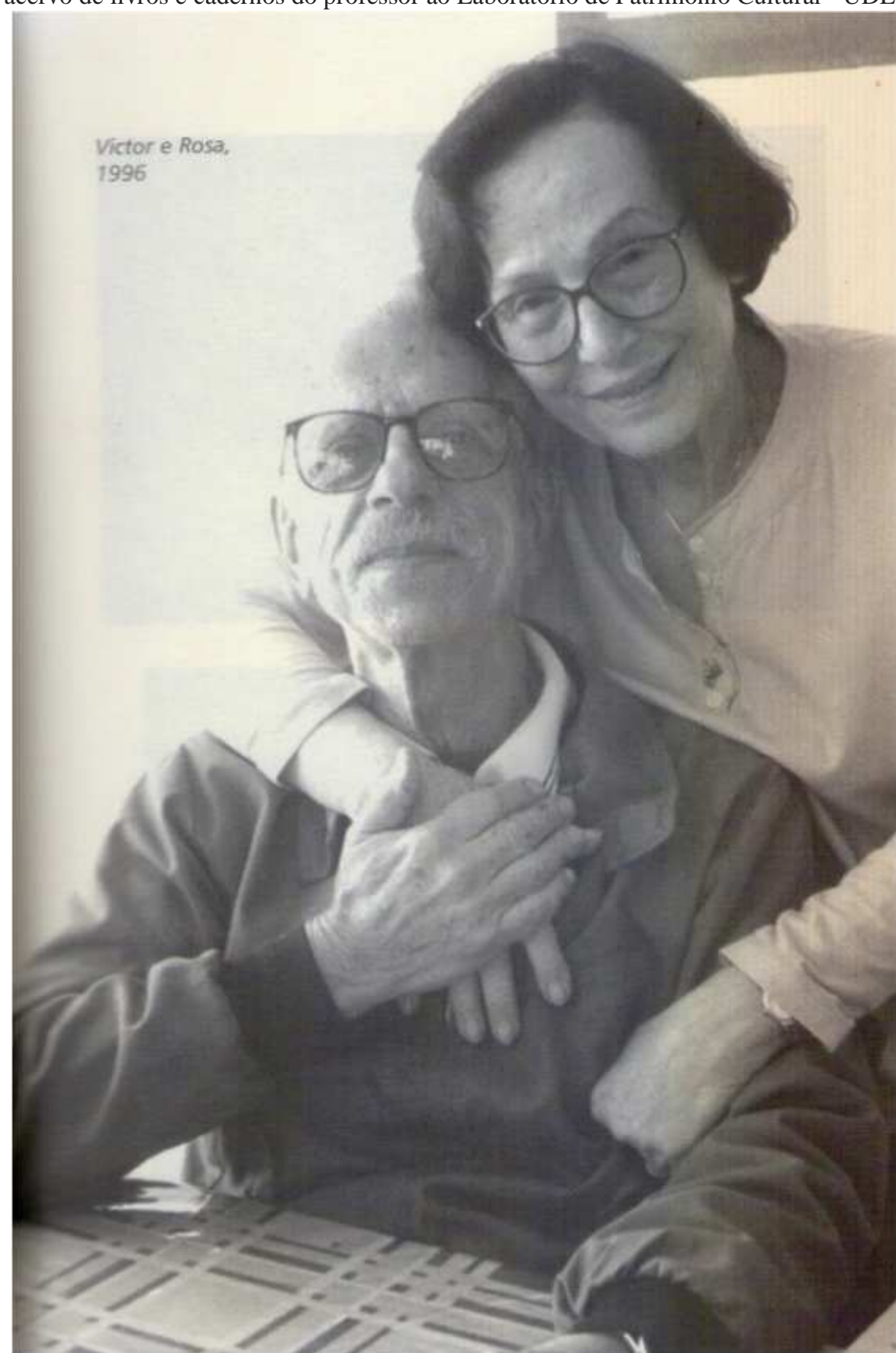

Fonte: KONDER, Rosa Weingold; RIBEIRO, Túlia de Freitas (org.). Victor Márcio Konder: um homem de múltiplas facetas. Florianópolis: IEA - Brasília: Instituto Tancredo Neves, 2006. 


\title{
CADERNOS DE UM PROFESSOR
}

\begin{abstract}
Os cadernos revelam modelos, exemplos e testemunhos, reais e fictícios, de distintas modalidades textuais, cuja coexistência, nesse espaço gráfico, expressa a pluralidade de matizes observáveis na escrita. (Antonio Castillo Gómez, 2012, p. 69).
\end{abstract}

O estudo dos cadernos marca uma das linhas de atuação e investigação como escrituras ordinárias $^{4}$. Eles mostram, igualmente, em traços firmes, uma relação pessoal com o universo da escrita e, por extensão, de uma História da Educação que se centra na análise das culturas tipográficas e nas estruturas e modos de operar da mente humana (CUNHA, 2009, 2011). A incorporação dessas questões e enfoques às pesquisas na área sinalizam para uma progressiva introdução da cultura escrita e da mentalidade letrada no acadêmico, abrindo-se outras possibilidades de conhecer diferentes maneiras de escrever e expor uma produção regrada, mas que sinaliza para uma atividade mais espontânea e até subjetiva (CASTILLO GÓMEZ, 2012, p. $68)$.

Quarenta e cinco cadernos escolares, utilizados nas décadas de 1970 e 1980, compõem o acervo de Victor Márcio Konder e foram recebidos, por doação da família, à própria pesquisadora. A catalogação até agora efetuada mostra que há três categorias: ligados a resquícios de um período de estudos, usados para anotações e reminiscência de aulas planejadas já como docente e marcados como aluno, do curso superior no Rio de Janeiro na década de 1970 e, notadamente de exercícios de aprendizagem da língua alemã.

Apresentados em suas capas originais, muitos deles fabricados pela FENAME (Fundação Nacional do Material Escolar/ Ministério da Educação e Cultura), eram popularmente conhecidos, nas décadas de 1960 é 1970, como "Cadernos do MEC" e vendidos a baixo preço e muito populares. Ao folheá-los pode-se encontrar traços incertos que dão ao desavisado leitor a impressão de terem sido escritos às pressas; as margens das páginas, anotadas ou rabiscadas, demonstram o aproveitamento irrestrito da página ocupada, demarcando assim, um território que julga ser seu. As letras irregulares ocupam folhas e mais folhas dos cadernos visados para, sem aviso prévio, serem interrompidas, sendo deixadas em branco muitas páginas vindouras. A escrita pode, ainda, dividir espaço com desenhos, ilustrações feitas à exaustão na quase completude da coleção; em sua maioria retratando traços humanos, perfis de homens adultos, anotações de cunho

\footnotetext{
${ }^{4}$ As escritas ordinárias ou sem qualidades são aquelas realizadas pelas pessoas comuns e que se opõem aos escritos prestigiados, elaborados com vontade específica de 'fazer uma obra' para ser impressa. (FABRE, 1993).
} 
político partidário como o resultado das eleições estaduais (SC) de 1970 e tais ilustrações fazemse ver, não raro, em páginas inteiras que evidenciam uma apropriação da tecnologia da palavra, típicas dos que trabalham com atividades ligadas ao pensamento.

Os cadernos apontam, também, para a possibilidade de estudos sobre a disposição do escrito na página, cuja ordem e desordem sinalizam para distintas modalidades textuais que descrevem percursos pessoais de um colecionador sedento pela eternização de fragmentos de sua biografia, na formação da sua imagem pública. Ao analisá-los como objetos de memória, o exercício da reflexão propicia o reconhecimento de seu consumo como suportes da cultura escrita, como a produção de significados pelos sujeitos que os produziram. "Significados que não se encontram imediatamente revelados ao nível da experiência sensível, mas que demandam um complexo trabalho de decodificação, análise, interpretação" (ABREU, 1996, p. 28).

Segundo Ana Chrystina Venâncio Mignot (2003), olhar papéis guardados por pessoas comuns, neste caso o caderno, é um convite para leituras diversas. Trata-se de fios que tecem a memória de uma família, uma instituição, uma época. Para pesquisadores, folheá-los significa iluminar a escrita ordinária dos incontáveis atores que se utilizam de suas folhas, linhas ou margens. São papéis que iluminam algumas pistas passíveis de investigação sobre a escrita íntima, despertando relações entre memória, escrita, sociabilidades, redes de poder, cotidianos, cultura escrita e arquivamento. A mesma autora discute a historicidade desse suporte de escrita e a necessidade de preservar estes materiais como importantes objetos e fontes de pesquisa (MIGNOT, 2008) e, sem dúvida seu trabalho pioneiro na área criou as condições para discutir este objeto em situação de história.

O conjunto do material analisado, encerra uma dupla condição em que aluno e professor se confundem no traço incerto de uma escrita apressada, tornando por vezes difícil saber qual, ao certo, a posição ocupada por Victor Márcio Konder, o "revolucionário letrado", como ele se auto intitulava no momento da escrita. Docente e discente têm a escrita frequentemente realizada por desenhos, traços que escondem perfis rascunhados em breves momentos de sossego, nas margens relegadas ao espaço próprio de criação. Os vazios da página, neste momento, ganham novos sentidos e significados, apontando para um momento de distração bem como para uma atividade motora facilmente realizável, uma vez que, como aluno ou professor, a caneta esferográfica simples é facilmente adquirível e, possivelmente, até mesmo já estava em punho. Os cadernos eram tanto refúgio de sua intimidade (desenhos, charges políticas) como instrumentos para 
registrar resumos de textos sobre autores identificados com aspectos econômicos de orientação marxista como Caio Prado Júnior e Nelson Werneck Sodré.

A coleção de cadernos, em bom estado de conservação, permite leitura quase plena de seu conteúdo; a letra regular e firme refere-se a diferentes temáticas, sendo que algumas se destacam. Nos materiais utilizados ainda no período vivido como discente do curso superior (1968-1972), destacam-se as anotações feitas matérias de antropologia e psicologia social, além das inúmeras anotações relativas à cadeira de economia. Nestes, a organização e uso de seu espaço gráfico mostra uma maior lógica ao pesquisador; as anotações organizam-se conforme pontos de discussão e temáticas maiores, tornando mais fácil seu entendimento. Percebe-se assim resquício da lógica institucional escolar, que delimita tempos e disciplinas e reverbera, da mesma forma, na escrita dos alunos. A organização gráfica é entendida como propiciada e incentivada por um ambiente temporal e espacialmente controlado pela lógica da instituição de ensino, culminando em uma escrita linear e cronológica que parece ter sido seguida pelo autor dos cadernos.

Nos exemplares entendidos como já inseridos em sua prática docente, é possível encontrar uma organização gráfica própria que dizem respeito a momentos e experiências vividas que foram guardados com afeto. Esta, provavelmente, fazia sentido para Victor Márcio mas mostra-se, ao pesquisador, de difícil entendimento. Pensamentos, elucubrações e devaneios dividem espaços da página com gravuras, padrões e escritos de cunho pessoal. A lógica institucional, embora presente na prática docente faz-se perceber em menor medida já que o agora professor não tem a vigília comumente dispensada ao aluno. O caderno, este precioso suporte de sua escrita, é agora seu, apenas seu, devendo ser plenamente compreendido por apenas ele; não necessita estudá-lo com fins de realização de provas e exames, nem tampouco mostrá-lo a professor algum. Todavia, tal fragmentação não inibe a tentativa de elaboração de uma memória edificada do colecionador e de sua coleção (RIBEIRO, 1998), sendo esta fortemente visível no acervo de Victor Márcio Konder, seja por meio de um panfleto, um bilhete, nota fiscal, lembrete, dando ao pesquisador novos elementos para entender o colecionador.

Diversas modalidades textuais habitam os cadernos da Coleção Konder: letras, rabiscos desenhos, charges, são primordiais peças na constituição de uma compreensão do processo educativo em determinados períodos e contextos históricos e seja a alunos como a professores criam condições, nas folhas, para breves espaços à transgressão de quem o escreve, comumente às margens e às páginas finais, sendo material valioso "quando se pretende examinar tanto a 
produção, circulação e usos dos suportes da escrita escolar como as práticas educativas, currículos e história das disciplinas escolares, por exemplo" (MIGNOT, 2008, p. 2).

Frutos da cultura material escolar, são transpassados por continuidades e descontinuidades; seu estudo abre portas a uma iluminação das relações entre escola e alunos e também as múltiplas materialidades e funcionalidades dos próprios cadernos. Embora utilizado de forma protocolar, é também campo de apropriações e criações, podendo abrir espaço, por vezes, a memória pessoal e familiar. Muitos, sobretudo pertencentes a docentes, são escritos para não serem mostrados, com bela caligrafia e constituindo-se em rastros de memória e possuindo exercícios, frases e planejamentos assumidamente inacabados (CUNHA, 2008).

Estudos sobre cadernos escolares e suas caligrafias mostram a pregnância desses materiais nas abordagens da história do tempo presente, tal como tematizam as autoras Bastos e Stephanou (2012, p.79), para quem:

\begin{abstract}
Cadernos de alunos de diferentes épocas constituem um observatório privilegiado das práticas da caligrafia historicamente experimentadas. Embora o acesso a esses cadernos seja considerado, em muitos casos e em relação a diversas experiências escolares, como escasso ou inacessível, empreendimentos de pesquisa vêm logrando alguns sucessos. A observação atenta desses artefatos, outrora de uso escolar, hoje objetos da memória familiar, possibilita mais do que o exame de uma materialidade ou dos processos de didatização do ensino da caligrafia e, portanto, dos temas de escrita e complexidade dos traçados. Também oportuniza uma reflexão acerca da produção de um determinado modo de ser e portar-se diante da escrita, particularmente como identidade do sujeito escolarizado.
\end{abstract}

A inscrição de si em um acervo e, mais especificamente, em cadernos escolares, nas letras e na figura de professor ou aluno, envolve uma prática reinvenção e reportação de si. Se na organização, seleção e salvaguarda de um arquivo, intenções e glorificação e formação de uma memória coesa em torno de si se fazem ver, a escrita em cadernos escolares, embora construída por aspectos semelhantes, obedece a novas regras, condizentes com a materialidade que suporta tal prática. Coordenados firmemente pelo tempo institucional, pela vigília de demais órgãos e profissionais, os tempos de escrita do caderno são próprios: respondem a uma ordenação de si de acordo com a disposição permitida pela escola na qual se estuda ou leciona. À invenção pessoal são relegadas margens, contracapas, folhas finais. Contudo, a lógica do escritor se faz ver na imagem de pequenas subversões: nas folhas em branco separando lições, nas margens desenhadas, nos versos transcritos. A lógica se ordenação e reinvenção de si percebida nos cadernos pertencentes ao acervo de Victor Márcio Konder obedece a prerrogativas institucionais, a uma mais próxima supervisão; todavia, esta não é suficiente para suprimir a vontade individual de 
desenhar ou escrever o que lhe vem à mente, ainda que em uma rápida caligrafia a ocupar margens e rodapés.

Ao procurar registros marginais, entendidos estes como escritos não autorizados por vozes institucionais, são iluminados alguns usos "não escolares" dos cadernos. Esta fonte, aparentemente banal, é também um suporte da escrita que deve ser desnaturalizado e problematizado. Importante registro do ensino e da aprendizagem escolar, o caderno é também um dispositivo iluminador da dinâmica e da interação que se dá dentro de sala de aula. Suas regras de uso no interior do espaço escolar, embora impostas, não são absolutas - uma escrita subversiva se manifesta em pequenas produções espontâneas corporificadas em registros não autorizados que remetem mais fortemente a traços pessoais do escritor.

O distraído professor rabisca algo na contracapa do caderno que tem em mãos; o desavisado aluno pula páginas, anota recados na contracapa. Ambos desenham firme e caprichosamente perfis de personagens, retratos de olhos, padrões de ilustração. Mais que território institucional de escrita, os cadernos de Victor Márcio, ao serem abertos, revelam mais que aluno e professor. Mostram traços, vestígios, fragmentos de um indivíduo inquieto, distraído, desavisado. A preciosa fonte comportada pelos cadernos escolares, uma vez desnaturalizada, é alvo de estudo, sem que neste sejam esquecidos os nomeados registros marginais. Fugidios e encolhidos, ou grandiosos e ousados, revelam traços da apropriação do aluno para com o conteúdo, mas também salvaguarda migalhas de sua subjetividade. Apontam o devaneio do professor em meio ao planejamento docente, iluminando vestígios de si e, também, mais profundas ideias ou veiculações ideológicas do aluno e do professor. Cadernos, folhetos, rabiscos são, assim, colocados a falar pelo historiador e como objetos em situação de conhecimento é que criam o sistema documental, são vetores de construção da subjetividade (MENESES, 1998, p. 96).

Vale ressaltar que na organização do material que chega ao arquivo após a morte do titular é comum ocorrer a interferência dos familiares, que resulta num rearranjo do acervo e, quando os conjuntos documentais são doados a uma instituição que abrigue tais materiais, outros atores, como arquivistas e bibliotecários, interferem no acervo, organizando-os de um modo que responda às demandas oriundas da pesquisa histórica. Essas interferências permitem refletir sobre a prática de guardar e preservar documentos como alvo de sucessivas manipulações e triagens.

Entre os procedimentos que, hoje, me parecem mais importantes, encontram-se o levantamento da história de cada fundo, o contato com as pessoas envolvidas na acumulação, ordenamento e guarda dos papéis - antes e depois da morte do titular -, bem 
como o investimento nas intenções, projeções e expectativas depositadas no arquivo por esse último, tanto no momento em que seleciona documentos para serem guardados como depois, ao vislumbrar a possibilidade de atribuir a seu acúmulo documental um valor histórico ou patrimonial. (HEYMANN, 2009, p. 55).

Figura 2: Conjunto de cadernos que pertenceram ao professor catarinense Victor Márcio Konder.

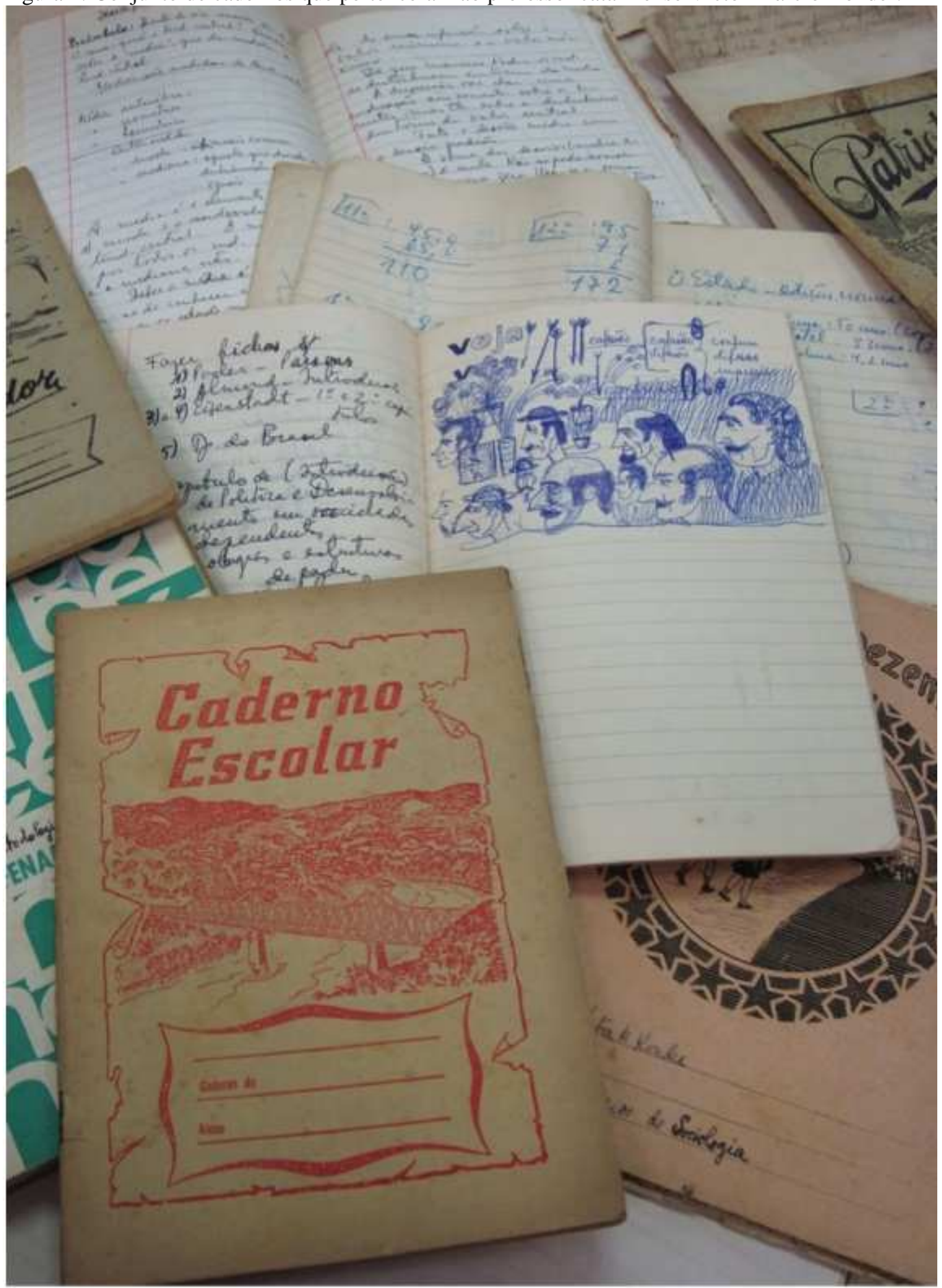

Fonte: Acervo de imagens de propriedade do Laboratório de Patrimônio Cultural - UDESC.

Rev. Iberoam. Patrim. Histórico-Educativo, Campinas (SP), v. 1, n. 1, p. 22-36, jul./dez. 2015 


\section{CONSIDERAÇÕES FINAIS}

Considerando este fundo documental, iluminado por outras possibilidades pôde-se, de um lado, ressaltar a dimensão da biblioteca de Victor Márcio Konder e se as práticas de escrita desse protagonista dadas a ver nas marcas deixadas nas anotações em seus cadernos pessoais, consolidam sua auto-referência de um "revolucionário letrado" e de um "intelectual". Nesse sentido, a problematização do acervo de cadernos pessoais permitiu traçar um perfil do leitor, compreender como lia e por que lia o sujeito em questão. A pesquisa indica, pois, para traços de uma atuação profissional, bem como registros em seus cadernos de atitudes pessoais de devaneio e lazer, ligados, ambos, a sua figura de intelectual. Como documento para a história da educação, este acervo pessoal se consolidou como um fértil campo de pesquisas e intervenções que auxilia e muito a prática do historiador do presente, sendo também tido como um meio de manter viva a memória de determinado colecionador.

Se o acervo, conforme aqui apresentado, é entendido como local de construção de uma memória coesa e edificada de si, onde o "eu" guardado sofre um processo de reorganização, processo semelhante, porém específico, se dá na escrita de si apreendida nos escritos dos cadernos estudados. O amplo espaço de escrita do caderno, embora comumente vigiado por normas escolares e institucionais abre, a quem o tem, um amplo leque de possibilidades e espaços para exercícios caligráficos e ilustrativos. Sua ocupação com planejamentos e exercícios se dá devido a seu uso profissional e estudantil, mas margens e páginas finais raramente escapam ao ímpeto criativo e evasivo do já exausto aluno ou professor. O aplicado aluno a transcrever exercícios, bem como o atento professor a planejar cada aula, é reportado como intelectual com firmes filiações ideológicas e implacável atenção. Contudo, esta imagem é, ao folhear das páginas, confrontada com gravuras firmemente desenhadas com caneta esferográfica e por demais anotações sem aparente nexo com o conteúdo anteriormente apresentado. Há, na escrita de cadernos, uma reinvenção de si, sendo esta regulada por normas e exigências institucionais. Todavia, margens, contracapas e bordas de folhas revelam, aos poucos, subjetividades e traços de uma personalidade vívida que se reinventa pela escrita.

A reordenação de si que compõe uma imagem coesa de um intelectual atento é confrontada por vestígios da personalidade do estudioso. Ao pesquisador é apresentada a figura do intelectual Victor Márcio, uma personalidade mais facilmente apreensível através dos registros 
marginais que estão inscritos em páginas, margens, contracapas. O caderno, este amplo território de escrita, embora submetido por firmes protocolos de ocupação e uso, dá ao escritor espaços de reapropriação e subversão. Ao atento historiador, estes se mostram como pedaços de uma trajetória de docente ou discente, sem que seja olvidado o sujeito escrevente. Atentar para estes novos documentos abre novos caminhos de pesquisa; uma vez descobertos, resta desbravá-los a partir das pistas que nos oferecem, pinçadas através de olhar atento. A adoção de novos instrumentos e objetos para estudo da história, sua problematização e análise, permitem o desbravamento de novos horizontes de pesquisa. A fabricação de si na escrita dos quarenta e cinco cadernos escolares de Victor Márcio Konder, o revolucionário letrado, é, pois, fruto destes novos paradigmas de pesquisa.

O acervo de cadernos, nascido da desordem e reordenado em meio ao caos (FARGE, 2009), ganha forma e toma corpo para o pesquisador. De seu meio, sobressaem-se estes cadernos, de quando aluno e já professor, todos já digitalizados, higienizados, lidos e analisados. Porém, em meio a firme escrita, sobressaem desenhos, gravuras, padrões ilustrativos, recados, panfletos, bilhetes... Traços de um percurso pessoal, de um sujeito personalizado na figura de um "revolucionário letrado" que, mais que aluno ou professor, é um sujeito que deixa rastros e se entrega, nas brancas páginas de seus cadernos, a momentos de devaneio e lazer.

Os cadernos escolares do Prof. Konder aqui utilizados na perspectiva de uma escrita "ordinária" se transformaram em um rico material para aprofundamentos sobre cultura escolar, em especial uma abordagem sobre formas de organizar o tempo escolar que fogem às convenções. A descrição de práticas e saberes escolares vividas no cotidiano e que, em geral, não estão visibilizadas nos grandes tratados educacionais nem na formalidade da legislação permitiu iluminar e apreender um conjunto de situações, fatos, experiências singulares, enfim, diferentes modos de funcionamentos do cotidiano escolar e da organização temporal da escola. Um material dessa natureza pode colocar à disposição do historiador um conjunto de práticas, sistematizadas em modelos, regras, temas, saberes que foram planejados e incorporados à organização escolar.

Assim, pode-se considerar que na condição de documento de uma época, os cadernos, ao exporem a organização das aulas e suas anotações variadas contribuíram para o estudo da história da educação inserindo-se no interior de um conjunto de representações que uma determinada sociedade, em um contexto histórico específico. Atualmente, musealizados, estes documentos impressos se impõem a nossos olhos e analisados assumem a condição de "objetos históricos" que 
ganham forma e densidade na medida em que estão em determinada situação (RAMOS, 2010): são testemunhos e servem de inspiração de atividades propostas e, como tal, são portadores de

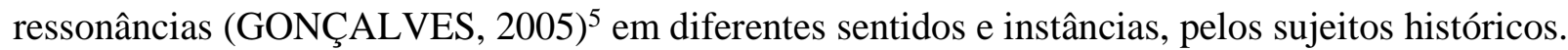

Os cadernos, aqui analisados na clave de documentos pessoais, se consolidam, pela investigação histórica como um fértil campo de pesquisas e intervenções que auxiliam a prática do historiador do presente. Nesse estudo sobre o ex-professor universitário, Victor Márcio Konder, o movimento até aqui realizado caminhou em duas direções: um "irrigar docemente o hoje com os encantos do ontem" ao mesmo tempo que se trabalhou com "o retorno do sujeito após um longo eclipse ao peso das estruturas", (DOSSE, 2009, p. 18). Exatamente por se enquadrar como tal, não pode ser usado de forma dissociada de demais procedimentos de pesquisa e análise - não deve haver uma pretensão de encontrar neles a verdade absoluta, bem como de edificar uma imagem estática de determinado indivíduo. O fazer diário da História passa a aceitar traços do cotidiano como meios de estudo, mas não os coloca em um patamar diferenciado em relação aos demais materiais. É ocupação do historiador o recorte de determinado tema, problema, e a divulgação dos resultados de sua pesquisa, estando sempre atento à legislação concernente aos documentos pessoais.

\section{REFERÊNCIAS}

ABREU, Regina. A fabricação do imortal: memória, história e estratégias de consagração no Brasil. Rio de Janeiro: Rocco. 1996.

ARTIÉRES, Philippe. Arquivar a própria vida. Estudos Históricos (Arquivos Pessoais). RJ: v. 11, n. 21, p. 09-32, 1998.

BARRETO, Cristiane Manique. Sinhá Corina: uma história de vida ou uma vida cheia de história para contar. In: MORGA, Antonio Emílio (org). História, cidade e sociabilidade. Itajaí (SC): Casa Aberta Editora, 2011, p. 137-161.

BASTOS, Maria Helena Camara; STEPHANOU, Maria. Da sensibilidade das mãos à harmonia da escrita: memórias, artefatos e gestos da caligrafia na história da educação. In: TRINCHÃO, Gláucia Maria da (org.). A caligrafia e a escrita: do desenho das belas letras à livre expressão do desenho da escrita. Feira de Santana: UFS, 2012.

\footnotetext{
${ }^{5}$ Por ressonância refere-se ao poder de um objeto exposto atingir um universo mais amplo, para além de suas fronteiras formais, o poder de evocar no expectador as forças culturais complexas e dinâmicas das quais ele emergiu e das quais ele é, para o expectador, o representante. (GREENBLATT, 1991, p. 41-56, apud GONÇALVES, 2005).
} 
CASTILlO GÓMEZ, Antonio. Educação e Cultura Escrita: a propósito dos cadernos e escritos escolares. Educação- PUCRS, Porto Alegre, v. 35, n. 1, p. 66-72, jan./abr. 2012.

COSTA, Cecília. Diário Carioca: o jornal que mudou a imprensa brasileira. Rio de Janeiro: Fundação Biblioteca Nacional, 2011, (cadernos da Biblioteca Nacional, 9).

CUNHA, Maria Teresa Santos; PHILIPPI, Carolina Cechella. Uma biblioteca sem ordem: Figurações em torno do acervo de livros de um intelectual do século XX. In: RAMOS, Francisco Régis L.; SILVA FILHO, Antônio Luiz Macêdo (organizadores). Cultura e Memória: os usos do passado na escrita da História. Fortaleza: Núcleo de Documentação Cultural - UFC/ Instituto Frei Tito Alencar, 2011, p. 302-315.

CUNHA, Maria Teresa Santos; SOUZA, Flávia de Freitas. Viver e escrever: cadernos e escritas ordinárias de um professor catarinense (Século XX). Florianópolis: Insular, 2015.

. Uma biblioteca anotada: caminhos do leitor no acervo de livro do Museu da Escola Catarinense. Florianópolis: UDESC/ CNPq, 2009.

Preces, cânticos, louvores: um ritmo para a construção do calendário escolar. In: FERNANDES, Rogério; MIGNOT, Ana Chrystina Venâncio (orgs). O tempo na Escola. Lisboa. Educa, 2008. p.139-150.

DOSSE, François. O desafio biográfico: escrever uma vida. São Paulo: Editora da Universidade de São Paulo, 2009.

FABRE, Daniel (org). Ècritures ordinaires. Paris: Centre Georges Pompidou: Bibliotheque Publique d'Informatión, 1993.

FARGE, Arlette. O sabor do arquivo. São Paulo: Editora da Universidade de São Paulo, 2009.

GONÇALVES, José Reginaldo. Ressonância, materialidade e subjetividade: as culturas como patrimônio. Horizontes Antropológicos, Porto Alegre, ano 11, n. 23, p. 15-36, jan./jun. 2005.

HEYMANN, Luciana Quilet. Indivíduo, memória e resíduo histórico: uma reflexão sobre arquivos pessoais e o caso Filinto Muller. Estudos históricos, Rio de Janeiro: CPDOC/FGV, v. 19, 1997. p. 41-60.

KONDER, Victor Márcio. Militância. São Paulo: Arx, 2002.

KONDER, Rosa W.; RIBEIRO, Túlia de Freitas (orgs). Victor Márcio Konder: um homem de múltiplas facetas. Florianópolis: IEA - Brasília: Instituto Tancredo Neves, 2006.

MENESES, Ulpiano Toledo Bezerra de. Memória e Cultura Material: Documentos Pessoais no Espaço Público. Estudos Históricos (Arquivos Pessoais). RJ: v. 11, n.21, p.89-103, 1998.

MIGNOT, Ana Chrystina Venâncio. Papéis guardados. Rio de Janeiro: UERJ, Rede Sirius, 2003. . (org.). Cadernos à vista: escola, memória e cultura escrita. RJ: EDUERJ, 2008. 
(org.). Lições de vida entre capas e contracapas. MIGNOT, Ana Chrystina Venâncio (org.). Não me esqueça num canto qualquer. Catálogo da exposição "Não me esqueça num canto qualquer", 2008.

RAMOS, Francisco Régis Lopes. As utilidades do passado na biografia dos objetos. In: RAMOS, Francisco Régis L.; SILVA FILHO, Antônio Luiz Macêdo (organizadores). Futuro do Pretérito: escrita da história e história do museu. Fortaleza: Inst. frei Tito de Alencar, Expressão Gráfica, 2010.

RIBEIRO, Renato Janine. Memórias e si, ou... Revista Estudos Históricos, Fundação Getúlio Vargas, v. 11, n. 21, p. 35-42, 1998.

ROTHBARTH, Marlene Dalva da Silva (org.). Família Marcos Konder Sênior. In: Famílias de Itajaí: mais de um século de história. Itajaí: Odorizzi, 2001. 